\title{
El autonomismo en Puerto Rico (1808-1898): la siembra de una tradición
}

\author{
María de los Ángeles Castro \\ UNIVERSIDAD DE PUERTO RICO \\ RECINTO DE RÍO PIEDRAS
}

\begin{abstract}
Para comprender a qué se debe la casi bicentenaria hegemonía de la doctrina autonomista en Puerto Rico, en este ensayo se analizan los orígenes de esta ideología y los fundamentos económicos y sociales que afianzaron su arraigo en la sociedad puertorriqueña contemporánea.
\end{abstract}

\section{$A$}

1 despertar el siglo XIX, mientras las colonias continentales de España en América optaron por romper con la metrópoli, Cuba y Puerto Rico aprovecharon la apertura que creó la guerra de independencia peninsular (1808-1814) para iniciar el debate político encaminado a reformular las bases del dominio español. Aunque no faltaron en dichas islas proyectos independentistas -en ocasiones vinculados a movimientos continentales- -1

1 Un ejemplo fue la conspiración lraguada en la villa de San Germán, al suroeste de Puerto Rico, en 1809. 'Tió, "Conspiración", 1963, pp. G-14. las circunstancias particulares de estas dos Antillas les marcaron rumbos propios a lo largo de toda la centuria. La intervención norteamericana en 1898 sancionó de manera definitiva las diferencias que habían ido superando paulatinamente las coincidencias entre las situaciones económicas, sociales y políticas de ambas islas: $\mathrm{Cu}$ ba logró su independencia de España al costo de pelear dos sangrientas guetras (1868-1878, 1895-1898). Puerto Rico, después de un fugaz ensayo de gobierno autonómico que culminó aspiraciones centenarias, pasó como botín de guerra a los norteamericanos. 
Las imposiciones coloniales de los invasores, entre ellas el regreso a un régimen militar centralizado y autoritario, reactivaron la lucha para redefinir las relaciones coloniales, esta vez con la nueva metrópoli estadunidense. La refriega política que ha dominado el siglo XX en Puerto Rico guarda significativas semejanzas con la del siglo anterior, sobre todo con algunas de las características dominantes como son el rechazo mayoritario a la independencia y el apoyo masivo a la opción autonomista. Cabe preguntarse entonces, a qué se debe la larga hegemonía de la doctrina autonomista, ya casi bicentenaria. Para comprenderlo es preciso rastrear los origenes de la ideología y dilucidar los fundamentos económicos y sociales que afianzaron su arraigo en la sociedad puertorriqueña contemporánea.

\section{LAS PRIMERAS SEÑNALS AUTONOMISTAS}

A juzgar por la entusiasta actividad que desencadenó la convocatoria para la asamblea que habría de celebrarse en el Teatro La Perla de Ponce del 7 al 9 de marzo de 1887 , la iniciativa para reorganizar el decaído Partido Liberal Reformista, fundado en 1870 , llenó de júbilo a los liberales criollos y a sus correligionarios peninsulares. La animación cundió por toda la isla reflejándose en los comités liberales de los distintos pueblos, reunidos para elegir sus representantes a la magna asamblea y sugerir ideas $y$ alternativas al Plan de Ponce. Llevó este nombre la propuesta que acompañó la convocatoria que circuló desde dicha ciu- dad, el 14 de noviembre de 1886, un grupo de liberales presididos por Román Baldorioty de Castro, intelectual puertorriqueño que había iniciado en la prensa, desde 1880 , una ardiente campaña en favor de la autonomía.

La situación no era para menos. Más de medio siglo después de sugerirse por primera vez la fórmula autonómica para el gobierno colonial, España legalizaba la discusión y reconocía a regañadientes la legitimidad de la aspiración de los liberales por esa forma de gobierno. El camino para alcanzar esta etapa fue largo y espinoso y los puertorriqueños pagaron un alto precio en la defensa de sus ideales. Debilidades propias y factores coyunturales, de orígenes metropolitanos, internacionales e insulares, explican la tortuosa senda liberal del siglo XIX y ayudan a comprender la euforia con que se emprendió la transformación clara y definitiva del Partido Liberal Reformista en Partido Autonomista Puertorriqueño.

La ideología autonomista sirvió de apoyo teórico a determinados sectores liberales, compuestos por propietarios y profesionales criollos y peninsulares, que buscaban resolver a través de la descentralización económico-administrativa los problemas que España no quiso o no pudo resolver durante el siglo XIX. Las razones del descontento con la metrópoli se señalaron sin equívocos ni vaguedades durante el periodo creado por la convocatoria y posterior celebración de las Cortes Constituyentes de Cádiz (1809-1812). Con motivo de orientar al diputado electo por Puerto Rico, el teniente de navío criollo Ramón Po- 


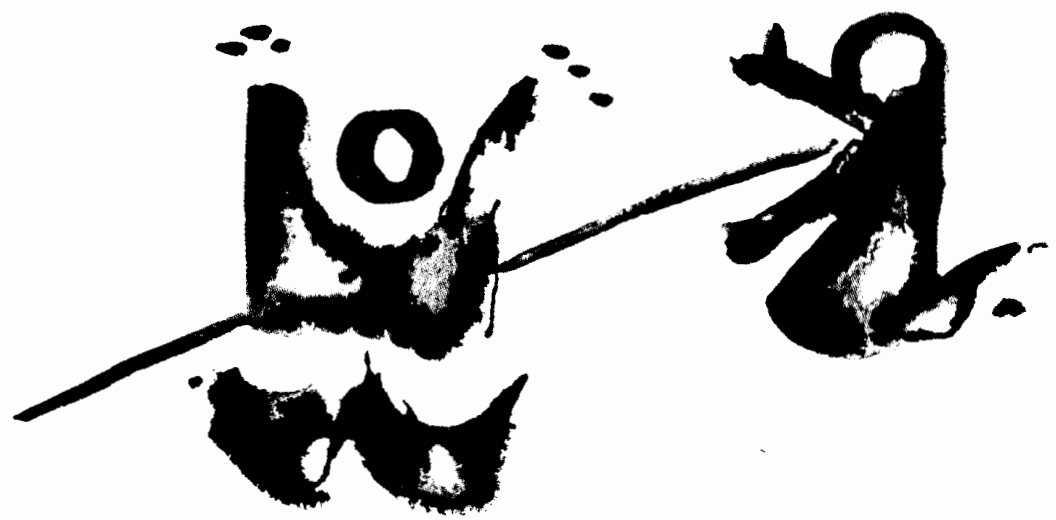

wer y Giralt, los cinco ayuntamientos de la isla le sometieron recomendaciones y peticiones específicas. Éstas constituyen un inventario de quejas contra el sistema imperate a la vez que un reflejo de las aspiraciones de los grupos dominantes de la sociedad colonial. Vale destacar cuáles eran las preocupaciones principales porque se repitieron invariablemente durante la centuria a modo de estribillo frente a la progresiva centralización y el fuerte autoritarismo del arbitrario y despótico régimen de los capitanes generales.

En conjunto, las denuncias y peticiones de los cabildos anticiparon el núcleo de las reformas autonomistas que los liberales solicitaron siempre que tuvieron una coyuntura favorable. Fueron constantes las quejas con- tra el oneroso sistema tributario, las restricciones comerciales, la falta de centros educativos -sobre todo a nivel superior, puesto que España se opuso reiteradamente a la fundación de una universidad en la isla ante el temor de que sirviera de nido revolucionario-, el rechazo a la participación criolla en la administración pública, el considerable atraso en la salud y en las obras públicas, y la amenazante presencia de extranjeros que comenzaban a desplazar a estancieros y ganaderos criollos de su frágil ascendencia social. Renglón aparte amerita la posición adoptada por los regidores frente a la necesidad de asegurar mano de obra estable dirigida a mover al campesinado hacia el trabajo asalariado en un momento en que se contem- 
plaba la reorientación de la economía de subsistencia hacia una agroexportadora, centrada en el azúcar. La preocupación expuesta fue una prioridad incesante de los hacendados y resumía varias inquietudes, entre ellas, el temor al crecido número de esclavos importados para trabajar primordialmente la caña de azúcar y las ideas liberales de que el trabajo libre era más rentable que el trabajo esclavo. ${ }^{2}$

Los primeros atisbos de la ideología autonomista se detectan en las instrucciones que sometieron los cabildos de San Germán (1809) y de San Juan (1810). Aprovechando el modelo de la Juntas Provinciales creadas en España durante la guerra de Independencia, propusieron el nombramiento de una junta insular, si bien con alcances diferentes. San Juan reclamó una Junta en la capital, a ser integrada por cinco hacendados y tres comerciantes, con injerencia en los asuntos de agricultura y comercio y en la infraestructura pública requerida para fomentar la economía agroexportadora. ${ }^{3}$ En otras palabras, lo que pidió para la Junta, aunque no lo llamara así, fue la autonomía en lo económico/administrativo. San Germán, más audaz, pidió el establecimiento de una Junta Provincial compuesta por el capitán general y el obispo (que era entonces el criollo liberal Juan Alejo de Arizmendi) y cinco diputados, uno por cada cabildo. Reclamó para ella "toda

2 Las peticiones de los cabildos y otros documentos relacionados a la participación de Power en las Cortes de Cádiz se reproducen en Caro de Delgado, Ramon Pouer, 1969. 80.

3 Caro de Delgado, Ramón Pouer; 1969, p. la autoridad superior gubernativa, militar y de Intendencia de la provincia" con injerencia "sobre los asuntos concernientes a favor de la nación y Estado, del bien y utilidad de la isla y sus habitantes...",4 es decir, autonomía completa: política y económico-administrativa.

De este modo, sin mencionar la palabra autonomía, se plantearon desde el mismo inicio del debate político en Puerto Rico las dos modalidades de la doctrina autonomista que se debatieron en distintos momentos del siglo pasado y que todavía hoy, con las variantes de rigor, se discuten bajo las fórmulas del Estado Libre Asociado (ELA) según lo configuró la Constitución de 1952 y la de la República Asociada, una versión mucho más avanzada del ELA que promueven con escaso éxito los sectores autonomistas más progresistas y soberanistas.

Power defendió en el foro peninsular la descentralización económicoadministrativa y la asimilación política. Sabía que en la atmósfera liberal de las Cortes de Cádiz era factible esperar la extensión de la Constitución a las provincias ultramarinas y con ella llegarían las garantías de los derechos ciudadanos, lo que sucedió en 1812. A los miembros de la clase social dominante que Power representaba, les convenía ese pacto que les daría a los criollos la oportunidad de participar en igualdad de condiciones con los peninsulares en el fomento económico y la administración de la colonia. A la vez, los derechos limitados a los que entraban en la catego-

${ }_{4}^{4}$ Ibid., p. 124. 
ría de ciudadanos marginaban a una considerable parte de la población, sobre todo de la mayoría negra y mulata, de los procesos electorales. 5 Por otra parte, la presencia del ejército peninsular garantizaba la seguridad de los propietarios frente a los esclavos cuyo número creció a partir de 1789 con la libertad de la trata y arreció con el auge de la industria azucarera.

El regreso de Fernando VII en 1814 y el retorno de España al régimen absolutista canceló los avances obtenidos en Cádiz hasta que el golpe de Riego en 1820 catapultó el trienio liberal. La nueva coyuntura constitucional permitió reanudar en Cortes la discusión de las formas ultramarinas. En esta ocasión, el carácter autonomista se expuso con mayor claridad en el Proyecto de instrucción para el gobierno económico-político de las provincias de ultramar, defendido, entre otros, por los cubanos Félix Varela y Leonardo Santos Suárez y el puertorriqueño José María Quiñones en las Cortes de 1823. El proyecto, como antes el de Power, combinó descentralización administrativa, en la que se perfilaba la Diputación Provincial como la institución medular para la administración de los intereses locales, con la asimilación política que descansaba en la extensión de los artículos de la Constitución de 1812 que garantizaban los derechos individuales del ciudadano. El Proyecto fue aprobado por las Cortes constitucio-

5 Náter Vázquez, "Autonomismos", 1991, pp. 102-103. Para Jas distintas disposiciones electorales cntre 1809 y 1875 , véase Tirado Merced, "Raíces", 1981, pp. 130-112. nales pero se frustró con la vuelta de España al régimen absolutista en $1823 .^{6}$

Las breves incursiones de los criollos puertorriqueños en la vida política durante los periodos constitucionales de $1809-1814$ y $1820-1823$, demostraron una tendencia reformista clara a favor de la descentralización económico-administrativa de la colonia y la asimilación política, entendida ésta como el disfrute de los mismos derechos civiles, políticos y jurídicos que los peninsulares. El retorno en 1823 a las arbitrariedades del despótico régimen de las Leyes de Indias y de los capitanes generales, endurecido por el eco de la independencia de las colonias continentales y las amenazas -reales e imaginarias- que se cernían sobre las Antillas españolas, logró acallar por un tiempo las voces liberales pero no pudo suprimir las ideas. Éstas permanecieron latentes, con manifestaciones esporádicas en diversos medios, hasta que una nueva coyuntura metropolitana e internacional les permitió retomar su senda.

\section{LA JUNTA INFORMATIVA DE RFFORMAS}

Con el propósito declarado de atender el escurridizo problema de las reformas ultramarinas prometidas en la Constitución de 1837 , se convocó a

6 proyecto de instrucción, 1823, sc custodia en el Archivo General de Indias, Indiferente, leg. 1323. Véase también a Cruz Monclova, Historia, vol. I, pp. 193-199 y Náter Vázqucz, "Autonomismos", 1991, pp. 103-107. 
Madrid a un grupo de representantes cubanos y puertorriqueños para que, junto a los comisionados peninsulares, discutieran los problemas coloniales y las cacareadas leyes especiales para las Antillas. Aunque los procedimientos deliberativos de la Junta Informativa de Reformas (1866-1867) estuvieron viciados, ésta dio la oportunidad a los criollos de expresarse en torno a las reformas sociales, económicas y políticas que favorecían a las islas. En la interesante exposición que suscitó la cuestión política, los liberales cuibanos y puertorriqueños presentaron un proyecto autonomista completo. Mediante planteamientos teóricos y la articulación de un programa de autogobierno, combinaron la crítica al sistema opresivo y unilateral de la metrópoli con la propuesta de un sistema racionalizado que salvaguardaba los intereses locales a la vez que afianzaba la integridad nacional. En este momento, como antes en 1812 y 1823 , los delegados antillanos hablaron con la claridad que permitieron las circunstancias.

El programa propuesto descansaba en el principio de la variedad dentro de la unidad, recogido en la fórmula de la descentalización económico-administrativa y la asimilación política. Definía la asimilación como un medio de proceder para ejercer derechos políti$\cos ^{7}$ Dicho de otra manera: la entendía como una forma de crear la igualdad de condiciones para el ejercicio de derechos semejantes a los que disfrutaban los peninsulares. Se buscaba con ella la oportunidad de enfrentarse

${ }^{7}$ Informaci6n, 1867, vol. II, pp. 4, 105 y ss. a los problemas locales con derechos análogos a los que disfrutaban los peninsulares. El eje del régimen local, de carácter representativo, radicaba en las corporaciones insulares, los distritos provinciales y los municipios mientras que las obligaciones de la soberanía nacional se ejercerian mediante la representación a Cortes. ${ }^{8}$ Esta aseguraba a la vez la participación criolla en la votación de los presupuestos nacionales y en la aprobación de leyes de alcance general.

La propuesta autonomista ofrecía garantías suficientes para preservar la integridad del imperio español en las Antillas. La más importante de ellas fue reconocer en todo momento la soberanía de España como nación a la que pertenecían tanto los peninsulares como los nacidos en las provincias de ultramar. Así, el concepto de la variedad dentro de la unidad permitía coexistir cómodamente a las variantes regionales dentro de la unidad político-jurídica de la nación que las cobijaba a todas.? De esta manera, los autonomistas del 67 ratificaron la base asimilista de la doctrina, rasgo que la acompañó hasta el fin del imperio español y que continuó bajo postulados diferentes en el siglo XX.

Los autores reconocían como precedentes del proyecto los fueros especiales que disfrutaban vascos, aragoneses, catalanes, valencianos, extremenos y andaluces y los buenos resultados que evidenciaba la amplia descentralización que caracterizaba a

8 Ibid., pp. 4, 9-27, 105-112.

9 Náter Vázque», "Autonomismos", 1991, pp. 119-124. 
gobiernos como los de Bélgica, Suiza, Inglaterra y Estados Unidos. Insistieron constantemente en que el sistema autonómico se asentaba sobre atribuciones que estaban dentro de la tradición política española por lo que no ponía en peligro la integridad nacional. ${ }^{10}$ Fueron incluso más allá al presentar la autonomía como un dique de contención para retardar o evitar movimientos independentistas. ${ }^{11}$

A diferencia de lo que aconteció en el ramo de las reformas sociales, donde el tema de la abolición inmediata de la esclavitud separó a los liberales cubanos de los puertorriqueños, obligando a los últimos a presentar un informe independiente, la cuestión política no motivó disenciones mayores entre ellos. Al menos todos los delegados de la Comisión Política firmaron el informe y sólo dos de los representantes cubanos, José Antonio Saco y Calixto Bernal, se opusieron a la representación a Cortes. ${ }^{12}$ Los comisionados puertorriqueños fueron José Julián Acosta y Francisco M. Quiñones.

El proyecto autonomista presentado ante la Junta Informativa era inadmisible para la España canovista de entonces. La situación se complicó aún más para las Antillas al decretarse nuevos impuestos que agravaban la crisis económica existente mientras que en la península se agudizaron los problemas que desembocaron en la

10 Informacion, 1867, vol. II, pp. 36.37, 107-109.

11 Ibid., pp. 5, 19-20, 38-39, 44, 111.

12 Los votos explicativos respectivos pucden consultarse en la información, 1867, vol. II, pp. $47-87$ y $87-100$.
Revolución Gloriosa de 1868. A pesar del carácter liberal de los gobiernos metropolitanos que se sucedieron entre 1868 y 1874 , y la reanudación para las colonias del derecho de enviar diputados a Cortes, los estallidos independentistas de Lares (septiembre de 1868) y Yara (octubre de 1868) profundizaron los temores que despertaba la doctrina autonomista en las autoridades peninsulares y en los conservadores del patio que veían en ella la antesala de la independencia.

Las persecuciones y los encarcelamientos que se sucitaron en Puerto Rico a raíz de Lares y las repercusiones de la Guerra de los 10 Años en que se prolongó el Grito de Yara en Cuba, dejaron una fuerte impronta en los espíritus liberales de ambas Antillas y en los gobiernos que se sucedieron en España. El momento no era propicio para debatir reformas autonomistas.

El PARTido libiral. Reformista: ASIMILISMO Y AITTONOMISMO

DE LA MANO

Las corrientes políticas existentes en Puerto Rico nacidas a principios del siglo XIX cristalizaron en 1870 en el Partido Liberal Reformista y el Partido Liberal Conservador, transformados más tarde en Partido Autonomista Puertorriqueño (1887) y Partido Incondicional Español (1880) respectivamente. Los independentistas se vieron forzados a operar desde el extranjero o en el más absoluto clandestinaje. Algunos de ellos optaron por la vía reformista e ingresaron al Partido Liberal desmoralizados por la expe- 
riencia de Lares y convencidos de las escasas posibilidades de triunfo que auguraban las adversas condiciones que enfrentaban.

La historiografía puertorriqueña ha recalcado consistentemente el carácter asimilista del Partido Liberal Reformista como resultado de la preponderancia de los liberales asimilistas sobre los liberales autonomistas. Sin embargo, documentación descubierta recientemente y la relectura cuidadosa de textos conocidos tiende a confirmar que la asimilación fue un compás de espera impuesto por las circunstancias y no un postulado ideológico disgregador en las filas liberales. Aún más, como ha podido apreciarse, la asimilación política fue desde el principio parte intrínseca de la ideología autonomista y no una posición antagónica o contradictoria frente a ella. Esto quiere decir que, contrario a lo que tradicionalmente se ha sostenido de que la mayor parte de los liberales fue primero asimilista y evolucionó hacia la autonomía, es dable sostener que siempre fue mayoritariamente autonomista, que la versión autonomista que predominó desde principios de siglo incluyó siempre la asimilación política y que la fuerza de las circunstancias obligó a poner énfasis en la asimilación hasta tanto les fuera permitido debatir abiertamente la autonomia. En el fondo, se consideraron partes de una misma doctrina. Esta interpretación no descarta la posición del sector minoritario que lidereaba Baldorioty de Castro, favorecedor de la autonomía total, en lo político y en lo económico-administrativo, según el modelo canadiense en el que se rechazaba la representación en los parlamentos metropolitanos. ${ }^{13}$

En el corto espacio de este ensayo no es posible desarrollar todos los argumentos que apoyan esta interpretación pero sí resumir algunos de ellos. En primer lugar, deben entenderse los términos de asimilación y autonomismo en el contexto de lo expuesto claramente en la Junta Informativa de 1866-67. En el programa del Partido Liberal de 1870 no se definió con precisión el principio de descentralización económico-administrativa probablemente porque las circunstancias del momento -dos años después de Lares y Yara- no se lo permitieron. No obstante, podemos inferirlo a raíz de cómo se había definido tres años antes en la Junta Informativa de Reformas. El programa de 1870 reclamaba que se concediera la mayor suma de facultades a la Diputación Porvincial y a los ayuntamientos para que, atendida la distancia, pudieran resolver las cuestiones de exclusivo interés local. Ese mismo principio básico estuvo presente en la propuesta política presentada ante la Junta Informativa. Por otro lado, sería ilógico pensar que hubiesen retrocedido tanto conceptualmente en el término de tres años, limitándose genuinamente a la asimilación absoluta, cuando es más plausible pensar en la prudencia impuesta por la censura, en el temor despertado por las persecuciones y los encarcelamientos experimentados después de Lares y en el convencimiento real -avalado por la desalentadora expe-

13 "Ia asimilación I", Revista de Puerto Rico, 1886; Cruz Monclova, Baldorioty, 1966, p. 142. 
riencia de las Cortes del 69- de que la metrópoli no estaba en disposición de considerar la alternativa autonomista por la sospecha separatista que despertaba. ${ }^{14}$

Debe recordarse también que la asimilación se entendió en la Junta Informativa como igualdad para el ejercicio de los derechos políticos ...y de ninguna manera de igualdad completa en todos los medios de ejercitar esos derechos, porque tal igualdad-dadas las muchas circunstancias especiales por nadie desconocidas de nuestras islasproduciría necesariamente una verdadera desigualdad de condición. ${ }^{15} \mathrm{La}$ igualdad de derechos políticos constituiría la base del poder que les permitiría administrar los asuntos locales. Este modo de entender la asimilación explica por qué los liberales pudieron pedir en el programa de 1870 la asimilación completa, haciendo extensiva a esta isla en todos sus artículos el título I de la Constitución de la Monarquía, que trata de los derechos individuales sin otra diferencia que en lo relativo al sufragio. ${ }^{16}$ El sufragio se percibía como un medio para ejercer los derechos políticos y debía atenerse a las circunstancias prevalecientes

${ }^{14}$ Así lo advirtieron muchos líderes criollos y peninsulares. Véase las citas de Rafacl María de Labra y Francisco Cepeda Taborcías, republicanos peninsulares íntimamente vinculados a los movimientos autonomistas antillanos, en Cruz Monclova, Historia, vol. 11, p. 61, n. 58. Las idcas de llegar al autonomismo por la asimilación, en vista de que las circunstancias no permitían otra cosa, fueron expresadas en diversos escritos de ambos líderes.

is Informacion, 1867, vol. II, p. 105.

16 Bothwell y Cruz. Monclova, Documentos, 1975, pp. 30-31. en la isla, diferentes a las de la península. Así entendida, conforme al principio de unidad en la variedad, 17 la asimilación representaba un adelanto dentro del régimen prevalenciente entonces sin despertar los recelos de la palabra autonomía. Además, recogía la esencia de las aspiraciones liberales: garantía de los derechos individuales y la facultad para compartir con los peninsulares la administración de la colonia. ${ }^{18}$

En segundo lugar, debe revalorizarse el alcance que tiene la aceptación de la doctrina federalista en 1873 . La asimilación a la España republicana llevó al partido local a cambiar su nombre momentáneamente por el de Partido Federal Reformista. ${ }^{19}$ La política asimilista que prevaleció durante

17 "Autonomia", El Clamor del País, 1888.

18 Para un análisis del programa del Partido Liberal Reformista y las raices sociales de su liderato, véase la tesis ya citada de Tirado Merced, "Raíces", 1981, en particular las pp. 40-49 y 143-157.

19 Este paso encontró oposición en algunos micmbros del partido aduciendo razones prácticas. José Julián Acosta, presidente del Comité Central del Particlo, argumentó que ante la poca estabilidad que tcnía la República, se corría el riesgo de que dicha fórmula pudicra llegar a ser ilegal en Puerto Rico. Favoreció prescindir del endoso a una forma política en particular y que se retuviera el nombre de Partido Liberal Reformista de manera que todos los partidos nacionales tuvieran el deber de hacerle justicia. Acosta Quintcro, José Julián Acosta, 1965, pp. 414-415. Ia posición de $\Lambda$ costa fuc derrotada, pero el ticmpo le dio la razón. Al caer la república en España, Pucrto Rico confrontó tiempos difíciles bajo el represivo capitán gencral José Laurcano Sanz, quien tomó medidas de mayor centralización gubernamental y control social. Sobre este último tema véanse Gómcz Acevedo, Sanz, 1956 y Flores, "Orden", 1991. 
la primera república española no contradecía el principio de descentralización administrativa a que aspiraban los liberales del patio. La fallida constitución republicana descansaba sobre el principio representativo de gobierno y, en una clara división de poderes, mantenia los derechos individuales y convertía a Puerto Rico y Cuba en dos de los diecisiete estados que integrarían la nación española. Estos postulados federalistas están presentes en la ideología autonomista.

\section{0-1887: AÑOS DE ESPERANZAS Y CONFIICTOS}

La década del 80 abrió con perspectivas políticas más amplias para los liberales. Varios factores explican la apertura del gobierno para la discusión de las ideas autonomistas. Uno de los más importantes fue la pacificación de $\mathrm{Cu}$ ba en 1878 después de una década de cruenta guerra. También fueron significativas las decisiones del Tribunal de Imprenta de La Habana en 1881 y la de la Audiencia de Puerto Rico en 1882 declárando compatible la doctrina autonomista con la Constitución española de 1876.20 El dictamen permitió pronunciarse abiertamente a favor de la autonomía dentro de los cánones que imponía la censura de prensa y los recelos que la doctrina -aunque legalizada- despertaba en los sectores conservadores y metropolitanos.

20 "Nuestra”, 1888; “Autonomia” 1886, pp. 16-19; Barbosa de Rosario, Baldortoly, 1957, p. 41.
Fue también oportuna para los fines autonomistas la presencia del catalán Victor Balaguer en el Ministerio de Ultramar. Creía en la política de atracción y, contrario a Sagasta, jefe del gobierno peninsular que se negaba reiteradamente a aceptar la doctrina autonomista, veía en ésta el camino hacia la asimilación. Afirmaba que mientras los autonomistas invocaran el nombre de España y fueran fieles a su causa, ameritaban que con prudencia se les fueran otorgando las libertades que pedian en nombre del progreso. ${ }^{21}$

En este nuevo clima, un tanto ambivalente entre la permisividad y la censura, se intensificó la campaña autonomista, dirigida por Román Baldorioty de Castro desde el importante puerto azucarero de Ponce. Surgieron periódicos autonomistas en distintos puntos de la isla y si bien la censura limitó muchos de ellos a uno o dos números, no pudo eliminarlos a todos a pesar de las multas y los enfrentamientos continuos. Periódicos como La Crónica, La Revista de Puerto Rico, El Buscapié y El Clamor del País entablaron un implacable debate con los conservadores que se manifestaban en El Boletín Mercantil y en La Integridad Nacional. Pero los debates no se reducían a una lucha maniquea entre criollos-liberales y peninsularesconservadores. Los autonomistas no formaban un grupo homogéneo pues

21 Carta de Victor Balaguer al gobernador general de Cuba, Emilio Calleja, 8 de enero de 1887, Biblioteca Museo Victor Balaguer, micropelícula en el centro de Investigaciones Históricas de la Universidad de Puerto Rico, carrete 1. 
coexistian en sus filas liberales criollos y peninsulares de poder económico variado y de diversas inclinaciones políticas, que disentían públicamente en la prensa y privadamente en las reuniones del propio Comité Central del partido y en el seno de los comités locales. Merecen repasarse algunos de los motivos de discrepancia que terminaron por dividir las filas autonomistas en 1897.

El de mayores repercusiones tuvo que ver con el tipo o grado de autonomía que se pretendía. Los modelos de mayor influencia fueron el canadiense, que favorecía la autonomía absoluta, y el programa adoptado por los cubanos, más ligado a tradiciones hispánicas y derivado del presentado ante la Junta Informativa. Este último fue el que se adoptó finalmente en la Asamblea de Ponce en 1887, con el fuerte apoyo de líderes republicanos penínsulares como Rafael María de Labra, residente en España, y Francisco Cepeda y Manuel Fernández Juncos, periodistas establecidos en Puerto Rico. En realidad, esta fórmula coincidía plenamente con lo que en diferentes momentos del siglo habían apoyado mayoritariamente los liberales puertorriqueños: asimilación política y amplia descentralización económico-administrativa. Con ella quedaba asegurada la españolización del país. ${ }^{22}$

Los sectores más conservadores dentro del Partido Liberal se afianzaron en el credo asimilista puro y se opusieron a la transformación del Partido Liberal. Favorecían la identidad completa con las provincias peninsu-

22 "Autonomia", El Buscapté, 1886. lares y el mismo grado de descentralización administrativa que éstas disfrutaran. ${ }^{23} \mathrm{El}$ alcance de este asimilismo lo explicó con meridiana claridad Julián E. Blanco, uno de los fundadores y redactores de las Bases del Partido Liberal Reformista en 1870, con motivo de los debates internos que suscitó la reorganización de la colectividad en 1883:

[...] queremos tener la descentralización poca o mucha que exista en la península; y que en unión con ésta, continuaremos pidiendo se ensanche hata llegar a la meta de nuestros deseos, que debe ser y es necesariamente la misma; el mayor desarrollo posible de la vida local de cada pueblo, así en la provincia como en los municipios, dentro siempre de la unidad nacional. ${ }^{21}$

Aunque los asimilistas puros que persistieron en definir así su doctrina fueron más bien casos particulares que no impidieron la marcha de la colectividad y terminaron por retirarse de la vida política en 1887 , es importante recordarlos por tratarse de personas influyentes dentro de la corriente liberal por más de tres décadas. Cabe pensar que las persecuciones, destierros y encarcelamientos que rodearon los sucesos de Lares, padecidos por liberales leales ajenos a la conspiración, como fueron los casos

23 Nâter Vázquè,, "Autonomismos", 1991, pp. 152-155.

24 Carta de Julián E. Blanco publicada en lil Clamor del Pás, 31 de mayo de 1883 . A parcec reproducida en el Boletín IItstorico (19141917), vol. ix, pp. 219-225. Véase en especial la p. 223. También véase "Nutonomía", Pm/saganda, 1886, pp. 16-19. 


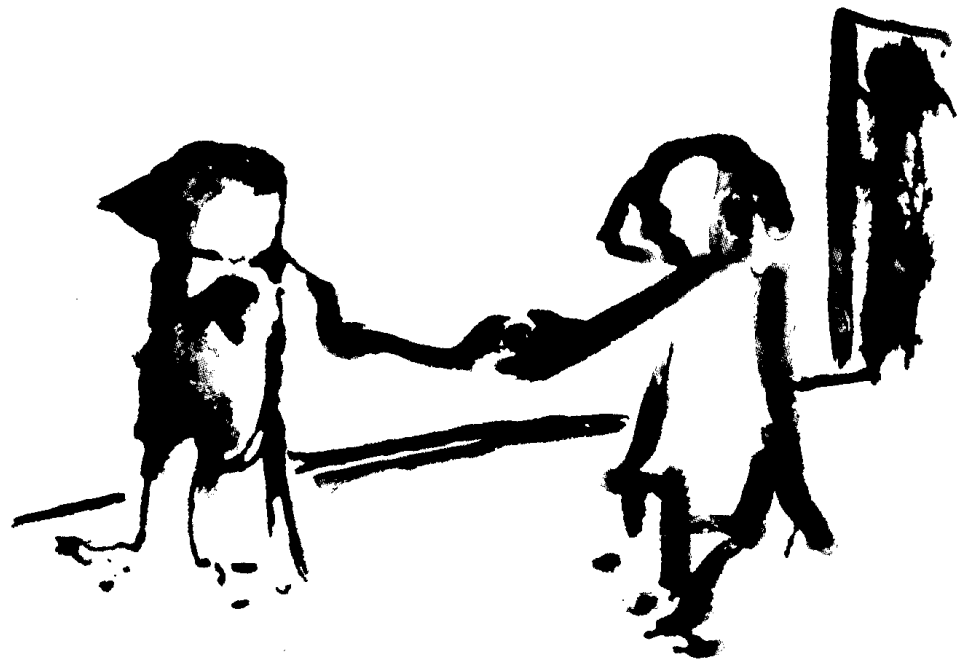

del propio Blanco y de José Julián Acosta, entre otros, pesó en sus ánimos. ${ }^{25}$ Más tarde, el regreso al sistema monárquico después de la república, con la que se había identificado el Partido Liberal Reformista, provocó las persecuciones de Sanz y la desmembración del partido. ${ }^{26}$ Tenían, pues, razones fundamentadas para temer represalias en caso de apoyar reformas mal entendidas por el gobierno

25 Véase Acosta Quintero, Jasé Julián Acosta, 1965, pp. 206-241; cl artículo "Vicio radical", Clamor, 1885, acepta que muchos liberales solian callar o no participar en los comicios electorales por temor.

26 Acosta Quintero, José Julián Acosta, 1965, pp. 424-426; Tirado Merced, "Raíces", 1981 , pp. 163-166. metropolitano y sus representantes en la colonia.

Tampoco debemos pasar por alto la influencia de la propaganda conservadora que veía en cada liberal -máxime en los autonomistas declarados- un independentista disfrazado, reforzando la desconfianza de las autoridades. $\mathrm{Si}$ aceptamos que un grupo político puede definirse parcialmente por sus contrarios, es viable pensar también que los asimilistas se empeñaron en competir con los conservadores en demostrar su lealtad a España. Ante el temor de ser tildados de separatistas, rehuyeron emplear el término autonomista e insistieron en la asimilación, a través de la cual podia llegarse a las reformas y a la descentralización administrativa a que aspira- 
ban y defendieron en la reorganización del partido ocurrida en 1883.

Algunas de sus manifestaciones demuestran el convencimiento de que la España de la Restauración, dominada por Cánovas y Sagasta, no llegaría a aceptar la autonomía como tal. Ante esa convicción optaron por la asimilación porque era lo que consideraban factible. ${ }^{27}$ Esta transacción marcaba un compás de espera en el que podrían obtener las reformas autonomistas a cuentagotas, sin aludir a términos alborotadores. ${ }^{28}$ Después de todo, a la altura de 1881 Sagasta persistía en catalogar de imposible el estado autonomista: "Nosotros vamos a la asimilación, pero a la autonomía jamás..."29 Seis años más tarde, los terribles componentes, desatados a raíz de la Asamblea de Ponce, demostraron que la perspicacia de los asimilistas, respecto a la reacción que podría traer la doctrina autonomista por parte del gobierno, no era infundada. Ni siquiera la revolución de Lares provocó una represión tan violenta, vejámenes y torturas del calibre de las que experimentaron los autonomistas $y$ otros criollos sospechosos, entre agosto $y$ noviembre de 1887 , "perseguidos con una saña que no guardó propor-

27 Náter Vázquez, "Autonomismos", 1991, pp. 155.

28 Véanse las versiones discrepantes del programa del Partido Liberal Reformista que reprodujo Bolivar Pagán, Procerato, 1961, pp. 163-164, y la que publican Bothwell y Cruz Monclova, "Documentos", 1975, pp. 30-31, reproducida del texto del asimilista puro Celis Aguilera, Mi grano, 1886. La carta de Julián Blanco antes citada confirma la versión de $\mathrm{Pa}$ gán.

${ }^{29}$ García Ochoa, Politica, 1982, pp. 49-50. ción con sus modestas metas de gobierno propio". 30

Sintiéndose profundamente españoles, los asimilistas puros miraban con recelo a sectores más progresistas dentro de su partido a los que consideraban "partidarios de la propaganda protestante $y$ admiradores de la civilización norteamericana". ${ }^{31}$ El temor se agravaba porque, en el reducido grupo separatista aglutinado en este partido, existió aparentemente un débil bando anexionista. Su presencia está relacionada con los intereses azucareros, intimamente ligados al movimiento autonomista y propulsores principales del librecambismo que les permitiría ubicar sus azúcares en los puertos norteamericanos. ${ }^{32}$

La relación del partido local con partidos externos también provocó amarguras. Los favorecedores de los partidos monárquicos debatían con los republicanos la conveniencia de asociarse con partidos peninsulares que respaldaran la doctrina autonomista e incluso con el Partido Liberal Autonomista de Cuba con el que compartían los principios fundamentales.

En la atmósfera descrita no deja de sorprender que los liberales superaran las diferencias y salieran de la Asamblea de Ponce como un solo partido explicitamente autonomista. Los

30 Garcia, "Autonomismo", 1987, S-7.

31 Carta de José Pablo Morales a José Julián Acosta, 21 de diciembre de 1865, en Colección María del Pilar Acosta Velarde de Legrand, Centro de Investigaciones Históricas, documento 5; "Corrientes anexionistas", El Buscapte, 1887.

32 Véase Domínguez, Autonomia, 1887; García, "Puerto Rico", Hisiorta critica, 1985, pp. 126-127; Picó, "Perspectivas", Al filo, 1993, pp. 195-205. 
unía el sentido de lealtad a España, a la que nunca disputaron la soberanía nacional, y el convencimiento absoluto de que la descentralización económico-administrativa era indispensable para superar los problemas que les ahogaban. El discurso del progreso y la modernidad fue parte fundamental de la argumentación autonomista, sobre todo en su debate eterno con los conservadores.

Pero el factor precipitante que concitó los descontentos y les dio un propósito común fue la grave crisis económica que enfrentaba la colonia. Mientras el cultivo del café, orientado hacia los mercados europeos, empezaba a rendir frutos para el interior montañoso, la caña y sus industrias derivadas, que conformaron el resorte económico que propició el desarrollo del país durante el siglo XIX, atravesaba una situación en extremo difícil. Se combinaban para ello las características estructurales vulnerables que prevalecían en el cultivo y la producción de azúcar, con las adversas condiciones de orden externo que regian el mercadeo internacional del producto. A la depresión ocasionada por los bajos precios en el exterior se sumaron los efectos de la abolición antes de que se hubiera creado un mercado de trabajo libre y los desaciertos tarifarios de España que no sólo gravaban la entrada de los azúcares antillanos por sus puertos sino que limitaban su acceso a los de Estados Unidos, compradores principales de la producción puertorriqueña y cubana. Los problemas monetarios ocasionados por el uso del devaluado peso de plata mexicano, las restricciones del crédito por la falta de instituciones financieras y la pobre infraestructura del país también incidian sobre los males de la industria. Además, como si no fuera poco el decaimiento de la agricultura costera y el estancamiento del comercio, los propietarios tenían que responder a un oneroso sistema contributivo y el país todo sobrellevar una arbitraria y desacertada distribución del presupuesto general en el que las partidas más jugosas se asignaban a Guerra-Marina y al Ministerio de Ultramar, mientras la más escuálida se dejaba para Fomento de la colonia. ${ }^{33} \mathrm{La}$ descentralización económico-administrativa que propugnaba la doctrina autonomista le permitiría al sector propietario del país contrarrestar estos escollos, mientras que la asimilación política les daría derecho de acceso a los cargos disponibles del gobierno local, necesario para impulsar y sostener las reformas.

En cierta medida, la crisis económica que aglutinó las distintas facciones autonomistas en 1887 también alimentó las grietas existentes en la colectividad. Lamentablemente, la composición social del partido autonomista no ha sido rigurosamente estudiada todavía, pero los trabajos de Astrid Cubano Iguina adelantan hipótesis interesantes sobre la configuración socio-económica de la clase propietaria dominante en el país y lo que parecen ser sus alineamientos políticos principales en las dos últimas décadas del siglo. ${ }^{34}$

33 Mejias, Crists, 1972.

34 Véase su libro Hilo, 1990, y sus artículos "Política", 1987-88 y "Paz" 1990. 
Ante la crisis azucarera, los grandes hacendados y comerciantes exportadores vinculados a ella insistieron en el librecambismo y en la transformación modernizadora de la hacienda - unidad productora tradicional- en la central, apoyada por capital proveniente del extranjero con préstamos e inversiones. Para alcanzar éstas y otras reformas favorables al desarrollo de la industria -como la creación de bancos agrícolas e hipotecarios- era menester obtener la autonomía administrativa. Por ende, recibió el respaldo de un grupo importante de profesionales e intelectuales que aspiraban a ocupar cargos públicos -para los que eran discriminados en favor de los peninsulares- $y$ que identificaron el progreso y la prosperidad del país con la suerte de los intereses azucareros. ${ }^{35}$ Destacados miembros de este último grupo, algunos de los cuales habían estudiado en Estados Unidos, demostraban una abierta preferencia por las formas republicanas de gobierno. También las favorecieron determinados sectores urbanos, entre los que figuraban artesanos y empleados afectados por el encarecimiento de la vida. ${ }^{36}$ Pero el apoyo de los artesanos y funcionarios menores podía tener escasas consecuencias electorales porque la ley electoral censataria limitaba considerablemente su participación en las urnas. ${ }^{37}$

35 Cubano lguina, "Paz", 1990, pp. 32, 34; García, "Puerto Rico", 1985; Picó, "Perspectivas", 1993, pp. 199-201.

36 Cubano Iguina, "Paz", 1990, p. 33.

37 Sobre la iniciación de los artesanos en la actividad política, véase García, "Primeras" 1990, pp. 217-227.
En contraposición al proyecto autonomista de lo 80 , se originó otro alentado por pequeños y medianos cafeticultores cuyo mercado principal estaba en España y Cuba; medianos y pequeños productores de azúcar mascabado que en medio de la crisis habían logrado estabilizar su situación (como ocurrió en la región de Arecibo); comerciantes exportadores asentados en los puertos y cascos urbanos que eran peninsulares en su mayoría; estancieros cultivadores de frutos menores de consumo interno y ganaderos. Fomentaban, en plena concordancia con el gobierno, la reorientación de la economía hacia la diversificación agrícola y el giro hacia el mercado peninsular e hispanoamericano. ${ }^{38}$ También formaron parte de este proyecto funcionarios públicos, miembros de los cuerpos militares y paramilitares en quienes recaía la defensa de la paz pública y el alto clero. La estrategia de este proyecto descansaba en el predominio de la mediana y pequeña propiedad en obvia discrepancia con la tendencia hacia el monocultivo y el latifundio de la expansión azucarera del litoral. ${ }^{39}$ Puede conjeturarse entonces que las particularidades personales y el grado de su adhesión a España $\rightarrow 0$ el modo como la entendian- dirigieron a los que compartían este proyecto económico hacia los flancos más moderados del liberalismo o a las filas más recalcitrantes del Partido Incondicional Español, defensoras del nacionalismo económi31.

38 Cubano Iguina, “Paz", 1990, pp. 15, 20, 39 Bid., pp. 22, 30-31. 
co que buscaba asegurar la hegemonía económica de España (sobre todo frente a la amenaza real de las fuertes relaciones mercantiles con los Estados Unidos), por medio del inmovilismo político que se traducía en la defensa acérrima de la integridad nacional.

Los estudios económicos que se han hecho hasta ahora de la sociedad decimonónica en Puerto Rico, revelan que las capas más altas de los sectores productivos y mercantiles estaban dominadas por peninsulares e inmigrantes extranjeros quienes también figuraban, esta vez en minoría, en los niveles medianos y pequeños. ${ }^{40} \mathrm{La}$ división de la clase propietaria dominante y la debilidad económica y social del sector criollo dentro de ella es uno de diversos factores que explican la amplia aceptación de la doctrina autonomista frente a la opción independentista y la prédica conservadora. De igual manera, acarreó motivos de disensión interna que, en combinación con otros ya mencionados, conjunto a la división del Partido Autonomista poco antes de que España, presionada por Estados Unidos y la guerra de Cuba, concediera el régimen autonómico a las dos Antillas en noviembre de 1897.

La invasión norteamericana en 1898 dio jaque mate al recién inaugurado experimento de gobierno propio. Mas la doctrina había calado hondo en las clases dirigentes del país que habían identificado el modelo fe-

40 Para los cambios que atañen a los conservadores en la década de 1890 , véase Cubano Iguina, "Política", 1987-88, pp. 202-203. deralista estadunidense con la forma perfecta de la autonomía. ${ }^{41}$ Por eso y porque en el fondo no variaron las condiciones socioeconómicas de las clases propietarias puertorriqueñas, no hubo grandes contradicciones cuando evitaron el reclamo indepenentista, anteponiéndole el autonomista. ${ }^{42}$

La naturaleza de las luchas políticas en Puerto Rico a lo largo del siglo XX es tema ajeno a este ensayo, pero no podemos concluirlo sin realcar la vigencia presente de algunas características esenciales del autonomismo decimonónico que han permanecido, atemperadas, desde luego, ante las exigencias del colonialismo en el mundo actual. Debe destacarse, sobre todo, la defensa de la unión permanente con la metrópoli de turno, los Estados Unidos, favorecida por un 94\% de los votantes en el plebiscito sobre estatus celebrado en $1993 .^{43} \mathrm{El}$ apego a la ciudadanía metropolitana, la participación parcial en los partidos nacionales, la representación -aunque sin derecho al voto- en el Congreso, la presencia en la isla de un Tribunal Federal y la demanda continua para que se incluya a la isla en proyectos federales que conllevan erogaciones presupuestarias, son parte del sustrato asimilista discutido a lo

41 "Doctrina", El Buscapie, 1886; "Corrientes", El Buscapié, 1887.

42 Véase Ramos Mattei, Sociedad, 1988, pp. 83-84.

43 Esta cifra se dividía entre $46.2 \%$ de los anexionistas favorecedores del estado federado, $48.4 \%$ del estado libre y un rezagado $4.4 \%$ de independentistas. Votaron el 73\% de los elegibles. El Nuevo Día, 1993; Rohter, "Choosing", Neu York Times, 1993. 
largo de este ensayo. El contrasentido que resulta de este estrecho pacto colonial con una nación de cultura diferente, ha sido desviado mediante un fuerte nacionalismo cultural y deportivo que ha suplantado de algún modo el nacionalismo conducente a la creación de una nación-estado independiente.

\section{BIBLIOGRAFIA}

-Acosta Quintero, Ángel, José Julián Acosta y su tiempo, Instituto de Cultura Puertorriqueña, San Juan de Puerto Rico, 1965.

-Barbosa de Rosario, Pilar, De Baldorioty a Barbosa. Historia del autonomismo puertorriqueño, San Juan de Puerto Rico, s.e., 1957.

-Boletín Histórico de Puerto Rico, ed. por Cayetano Coll y Toste, Tip. de Cantero Fernández y Cía., San Juan, 1914-1947, 14 vols.

-Bothwell, Reece y Lidio Cruz Monclova, Los documentos, ¿qué dicen?, Editorial de la Universidad de Puerto Rico, Río Piedras, 1975.

-Caro de Delgado, Lída R., Ramón Powery Giralt, diputado puertorriqueño a Las Cortes Generales y Extraordinarias de España. 1810-1812, San Juan de Puerto Rico, s.e., 1969.

-Celis Aguilera, José de, Mi grano de arena, Imprenta de Acosta, San Juan de Puerto Rico, 1886.

-"Corrientes anexionistas", en $\mathrm{El}$ Buscapié, 14 de agosto de 1887.

-Cruz Monclova, Lidio, Baldorioty de Castro Instituto de Cultura Puertorriqueña, San Juan de Puerto Rico, 1966.

-Cruz Monclova, Lidio, Historia de Puerto Rico (Siglo $X I X$ ), Editorial Universitaria, Rio Piedras, 1952-1964, 5 vols.
-Cubano Iguina, Astrid, El hilo en el laberinto: claves de la lucha polftica en Puerto Rico (siglo XIX), Ediciones Huracán, Río Piedras, 1990.

, "La política de la elite mercantil y el establecimiento del régimen autonómico en Puerto Rico (1890-1898)", en Boletín del Centro de Investigaciones Históricas, Universidad de Puerto Rico, núm 3, 1987-88.

- "Paz pública y propiedad territorial: la discusión sobre política agraria en Puerto Rico, 1880-1889", en Boletín del Centro de Investigaciones Históricas, Universidad de Puerto Rico, núm. 5, 1990.

-"Doctrina democrática", en El Buscapié, 26 de diciembre de 1886.

-Domínguez, José de Jesús, La autonomía administrativa en Puerto Rico, Tipografia Comercial, Mayagüez, Puerto Rico, 1887.

-El Nuevo Día, 15 de noviembre de 1993.

-Flores, María Margarita, "Orden público, centralismo y represión en el puerto Rico del siglo XIX", tesis de maestría, Universidad de Puerto Rico-Departamento de Historia, Río Piedras, 1991.

-García, Gervasio Luis, "El autonomismo en perspectiva", en El Nuevo Día, Suplemento, 19 de noviembre de 1987.

los honrados hijos del trabajo: 1873 $1898^{\prime \prime}$, en Boletín del Centro de Investigaciones Históricas, Universidad de Puerto Rico, núm. 5, 1990.

—, "Puerto Rico en el 98: comentarios al Informe Carroll" en Historia críttca, historia sin coartada. Algunos problemas de la historia de Puerto Rico, Ediciones Huracán, Río Piedras, 1985.

-García Ochoa, María Asunción, La política española en Puerto Rico durante el siglo $X I X$, Editorial de la Universidad de Puerto Rico, Río Piedras, 1982.

-Gómez Acevedo, Labor, Sanz, promotor de la conciencia separatista, Iditorial Universitaria, San Juan de Puerto Rico, 1956. 
-Informacion sobre reformas en Cuba y Puerto Rico, Imprenta de Hallet y Breen, Nueva York, 1867, 2 vols.

- "La Asimilación I", en Revtsta de Puerto $R i c o, 1$ de septiembre de 1886.

- "Ia autonomía colonial", en Propaganda reformista. La autonomía en Cuba y Puerto Rico, Imprenta de Marcelino Burgase, Madrid, 1886.

- "La autonomía entre la razón y la ciencia", en El Clamor del País, 18 de agosto de 1888 .

- "La autonomía se impone", en El Buscapté, 19 de septiembre de 1886.

-Mejlias, Félix, De la crists económica del 86 al año terrible del 87, Ediciones Puerto, Puerto Rico, 1972.

-Náter Vázquez, Laura, "Los autonomismos: de la semilla al proyecto (1809$18877^{\prime}$, tesis de maestria, Universidad de Puerto Rico-Departamento de Historia, Río Piedras, 1991.

-Nuestra doctrina", en Revista de Puerto Rico, 9 de marzo de 1888.

-Pagán, Bolivar, Procerato puertorriqueño del siglo XIX (Historia de los partidos politicos puertorriqueños desde sus origenes hasta 1898), Editorial Campos, San Juan de Puerto Rico, 1961.

-Picó, Fernando, "Perspectivas de la investigación histórica sobre el autonomis- mo en Puerto Rico a fines del siglo XIX" en Al filo del poder. Subalternos y dominantes en Puerto Rico, 1739-1910, Editorial de la Universidad de Puerto Rico, Río Piedras, 1993.

-Proyecto de instrucción para el gobierno económico-político de las provinctas de ultramar, Imprenta de D. Tomás Albán y Compañía, Madrid, 1823, en el Archivo General de Indias, Indiferente, leg. 1323.

-Ramos Mattei, Andrés A., La sociedad del azúcar en Puerto Rico, 1870-1910, Universidad de Puetto Rico, Río Piedras, 1988.

-Rohter, Larry, "Choosing Status Quo", en The New York Times, 16 de noviembre de 1993.

-Tió, Aurelio, "La conspiración de San Gérmán de 1809", en Revista del Instituto de Cultura Puertorriqueña, núm. 19, abril-junio 1963.

-Tirado Merced, Dulce María, "Las raíces sociales del liberalismo criollo: el Partido Liberal Reformista (1870-1875)", tesis de maestría, Universidad de Puerto RicoDepartamento de Historia, Río Piedras, 1981.

-"Vicio radical", en lil Clamor del País, 15 de agosto de 1885. 